\title{
Torrefaction of Portuguese woody biomasses and the evaluation of its properties
}

\author{
L.J.R. Nunes ${ }^{1}$, R. Godina ${ }^{2}$, J.C.O. Matias ${ }^{1,2}$, and J.P.S. Catalão ${ }^{2,3,4}$ \\ ${ }^{1}$ GOVCOPP and DEGEIT, University of Aveiro, 3810-193 Aveiro, Portugal \\ ${ }^{2}$ C-MAST, University of Beira Interior, 6201-001 Covilhã, Portugal \\ ${ }^{3}$ INESC TEC and Faculty of Engineering of the University of Porto, 4200-465 Porto, Portugal \\ ${ }^{4}$ INESC-ID, Instituto Superior Técnico, University of Lisbon, 1049-001 Lisbon, Portugal \\ e-mails: leonelnunes@ua.pt, rd@ubi.pt, jmatias@ua.pt, catalao@,fe.up.pt
}

\begin{abstract}
Torrefaction is an option for improving biomass properties for fuel application. Biomass undergoes chemical changes reflected on the upgrading of its properties as a biofuel, such as higher calorific power, lower $\mathrm{O} / \mathrm{C}$ and $\mathrm{H} / \mathrm{C}$ ratios, lower higroscopicity or better grindability. The objectives of this experimental study were to analyze the effects of torrefaction, under standard conditions of $265^{\circ} \mathrm{C}$, and residence time of 15 minutes in a nitrogen atmosphere and during a total $1 \mathrm{~h} 45 \mathrm{~m}$ heating period, on a set of sixteen woody biomasses coming from poplar short rotation coppice (SRC) and other Portuguese roundwoods. Average mass loss was higher than $40 \%$. The set of poplar clones and common broom provided torrefied products with higher quality than the set of roundwood forest species. The results on other parameters for proximate and ultimate analysis corroborate this global picture. Correlation analysis showed a higher degree of interconnectedness between LHV and proximate analysis results, for poplar clones and common broom, comparatively with roundwood biomasses.
\end{abstract}

\section{Key words}

Woody biomass, Torrefaction, LHV, Fixed carbon gain, Volatiles loss

\section{Introduction}

In Portugal, forest areas make up about $35 \%$ of the territory and shrubland and pasture about $32 \%$. eucalyptus (Eucalyptus globulus) and maritime pine (Pinus pinaster) figure among the main important forest species with an occupation of about 810 thousand hectares and 714 thousand hectares, respectively. Acacia species such as sally wattle (Acacia melanoxylon) and silver wattle (Acacia dealbata), considered as invasive, occupy about $0.2 \%$ of the forest area [1].

For evaluating the forestry potential of these acacia species, it can be mentioned than sally wattle and silver can exhibit higher performance for Kraft pulping than Eucalyptus Globulus [2].

Mature poplar is included in the class "other deciduous" in the Portuguese Forest Inventory with a total area in the country not higher than 5000 hect., very small, given the potentialities of this species [3].
Common broom (Cytisus multiflorus) is one the woody perennial shrub species available, also prone to conversion for bioenergy. This is a shrub species covering vast forest areas, leading to the production of large quantities of residual biomass that could be used as a sustainable raw material, available for the production of bioenergy or chemical products. Broom fibers with cellulose amounts as high as $90 \%$ can be extracted and potentially used in fields such as textile, paper, composites etc. [4].

Short rotation coppice (SRC) cultivations mainly of hardwood species, such as poplar, although yet without any implementation in Portugal, are another potential source of bioenergy in non-occupied or in pasture or shrub land areas [5]-[7].

Biomass torrefaction, although not spread on a larger commercial scale, has attracted major interest in the last 20 years ([8]).

In this entire context, the present work intended to evaluate the physical and chemical properties and mass yields of torrefied products of 17 woody biomasses, corresponding to: 9 poplar SRC clones the from Belgium and Italy, 6 Portuguese relevant forest species which were maritime pine, stone pine, eucalypt, silver wattle, sally wattle, and mature poplar and to common broom, a native shrub species in central Portugal. This experimentation involved a large set of feedstocks typifying a broad range of wood biomasses from juvenile hardwoods to shrubs and mature softwoods and hardwoods.

The main objectives of this work were thereby:

(i) to test if the type or structure of the woody biomass would, under equal operative conditions, influence the performance of the torrefaction, whether on torrefied product calorific properties on chemical composition or on mass yields and

(ii) to evaluate if in a forest prone country as Portugal, the experimental results on woody biomass torrefaction would allow to consider this thermal treatment as a viable option for improving the aptitude of this kind of biomass for the production of bioenergy. 


\section{Material and methods}

Sixteen trials of torrefaction were performed with a laboratorial Nabertherm rotary reactor, on the Portuguese company YGE - Yser Green Energy SA.

The 9 poplar SRC clones used in the torrefaction experiments were Brandaris (Populus nigra), Grimminge (Populus deltoides $\mathrm{x}$ (Populus trichocarpa $\mathrm{x}$ Populus deltoides)), Wolterson (Populus nigra), Skado (Populus trichocarpa $\mathrm{x}$ Populus maximowiczii), Hees (Populus deltoides x Populus nigra), Bakan (Populus trichocarpa $\mathrm{x}$ Populus maximowiczii), Ellert (Populus deltoides $\mathrm{x}$ Populus nigra), AF8 (Populus generosa x Populus trichocarpa) and AF2 (Populus deltoides $\mathrm{x}$ Populus nigra).

The biomasses from Portuguese roundwood species corresponding were collected from trees of 6 forest species: eucalyptus (Eucalyptus globulus), silver wattle (Acacia dealbata), stone pine (Pinus pinea), sally wattle (Acacia melanoxylon), maritime pine (Pinus pinaster), and poplar (Populus alba). Woody biomass common broom (Cytisus multiflorus) a native shrub species from Central Portugal was also used.

The 16 woody biomass samples weighed about $1 \mathrm{~kg}$ each on a dry basis, and the torrefaction experiments were performed at an $\mathrm{N}$ atmosphere under a temperature of $265^{\circ} \mathrm{C}$, and residence time of 15 mins on a total $1 \mathrm{~h} 45 \mathrm{~m}$ heating period. Proximate and ultimate analysis were carried out with raw and torrefied materials. The equipment and norms used for proximate analysis, ultimate analysis, HHV and LHV were, respectively:

- Proximate Analysis: Proximate analysis (TGA), including the determination of torrefied material moisture, volatile matter and ash content, was carried out using an ELTRA Thermostep, following ASTM D758212.

- Ultimate analysis: Torrefied material carbon, hydrogen and nitrogen contents were evaluated using a LECO CHN628, following standard operating instructions. Low heating value (LHV) was measured through a Parr 6400 calorimeter, based on the standards EN 14918 (2009) and EN 15296 (2011) and the equipment's standard operating instructions.

From the results of proximate, ultimate analysis and HHV data, three correlation analyses were performed on databases relative to the: whole set biomass samples, biomasses from poplar SRC and common broom and the biomasses from roundwood, respectively. The correlation analysis was performed to find some correlation pattern between torrefied biomass variables, quantifying thereby interactions between them.

\section{Results}

\subsection{LHV, proximate analysis and mass loss}

Overall, the set of SRC and common broom torrefied biomasses show a profile wherein LHVs, fixed carbon, gain in fixed carbon, loss of volatiles, and percent mass losses for torrefied products are higher. Volatiles percent amounts of these torrefied biomasses are also lower than the amounts for the set of torrefied biomasses from roundwoods.
Indeed, biomasses from poplar clones have LHV values averaging $23.8 \mathrm{MJkg}^{-1}$, and ranging between $22.43 \mathrm{MJkg}^{-}$ ${ }^{1}$ (clone AF2) and $25.05 \mathrm{MJkg}^{-1}$ (clone Skado).

Torrefied biomass of common broom has a LHV of 23.81 $\mathrm{MJkg}^{-1}$. LHV of torrefied biomasses from roundwoods averaged $22.03 \mathrm{MJkg}^{-1}$, ranging between $21.06 \mathrm{MJkg}^{-1}$ (eucalyptus) and $22.60 \mathrm{MJkg}^{-1}$ (maritime pine).

Also, the percent mass losses of poplar clones from torrefaction were on average $46.74 \%$, ranging between $43.21 \%$ (clone Brandaris) and $49.77 \%$ (clone Grimminge).

The correspondent values for roundwood biomasses averaged $41 \%$, ranging between $37.44 \%$ (maritime pine) and $49.5 \%$ (silver wattle). The mass loss of common broom is $43.83 \%$.

The percent LHV gains of torrefied biomasses from poplar SRCs were also higher, averaging $28.22 \%$ and ranging from $21 \%$ (clone AF2) to $36 \%$ (clone Skado). The LHV gain of common broom was $25 \%$. The percent LHV gain of roundwood was $20.3 \%$, ranging between $17 \%$ (stone pine and eucalypt) and $25 \%$ (silver wattle and poplar).

The fixed carbon $(\%, \mathrm{db})$ was higher in torrefied biomasses from poplar SRC, averaging 36.55\% and ranging from $31.36 \%$ (clone $\mathrm{AF} 2$ ) to $41.80 \%$ (clone Bakan). The correspondent value for torrefied common broom biomass was $35.89 \%$. The percent fixed carbon on a dry basis for torrefied roundwoods averaged 30.05\%, ranging from $29.33 \%$ (eucalyptus) till $33.5 \%$ (silver wattle).

The gains on fixed carbon were also higher in torrefied biomasses from poplar SRC averaging $48.38 \%$ and $38.27 \%$ in torrefied biomasses from roundwoods. The gain in fixed carbon for torrefied biomass from common broom was $53.4 \%$, or the same order of magnitude as for torrefied biomasses from clone Hees $(53.15 \%)$ and from clone Wolterson (53.01\%). Clones Bakan and Skado also showed gains on fixed carbon higher than $50 \%$. As for torrefied biomasses from roundwoods, mature poplar was the species with higher fixed carbon gain (44.6\%).

The volatiles percent amount was lower in torrefied biomasses from poplar SRC, averaging $60 \%$, with the smaller amount for clone Hees $(54.66 \%)$. Clone Skado, with the highest LHV, showed $59.79 \%$ of volatile content and maximum volatile amount in poplar clones was $66.13 \%$ (clone AF2). The volatile percent amount for torrefied common broom was $61.28 \%$.

The average volatile amounts for torrefied biomasses from roundwood were lower than $71.60 \%$ (sally water) averaging $67.8 \%$. The volatiles loss was higher for torrefied biomasses of poplar clones, comparatively to torrefied biomasses from roundwoods, averaging 24\%, ranging between $17.3 \%$ (AF2) and 29.9\% (Hees).

The volatiles loss for torrefied biomasses from common broom was $24.8 \%$. The average volatiles loss of torrefied biomasses from roundwoods was $16.1 \%$, with the higher value for mature poplar biomass (18.1\%).

The ash amount in the torrefied biomasses from poplar clones was higher, averaging $3.1 \%$, than in torrefied biomasses from roundwoods, averaging $1.7 \%$.

The ash gain for torrefied biomasses from poplar clones averaged $56.1 \%$, ranging between $28.5 \%$ (Wolterson) and $79 \%$ (Skado). 
The average ash gain for torrefied biomasses from roundwoods averaged $46.6 \%$, ranging from $23.3 \%$ (maritime pine) till 88\% (eucalyptus). Ash gain for torrefied biomass from common broom was $64 \%$.

Figure 3 depicts the clear distinction of torrefied biomasses of poplar clones and common broom on the variables: LHV (\%), loss of volatiles (\%), fixed carbon (\%) and LHV gain (\%). Figure 4 shows the differences between the same two sets of biomass, concerning the variables: gain in fixed carbon $(\%)$, volatiles $(\%)$, LHV gain $(\%)$, and loss of volatiles (5).

\subsection{Elementary analysis}

The elementary carbon amounts were higher for the poplar clones, averaging $66.4 \%$, and ranging between $63.5 \%$ (Wolterson) and $68.3 \%$ (Grimminge). The percent elementary carbon amount for torrefied biomasses from common broom was $68.2 \%$. For the roundwoods torrefied biomasses the average elementary carbon amount was $63 \%$, ranging between $57.2 \%$ (silver wattle) and $65.6 \%$ (poplar). The $\%$ gains in elementary carbon were also higher in biomasses from poplar clones, averaging $28 \%$, and ranging between 22.4\% (Wolterson) and 30.9\% (Grimminge). The percent elementary carbon amount gain for torrefied biomasses from common broom was $22.8 \%$. The correspondent values for torrefied biomasses from roundwoods averaged $16.7 \%$, ranging between $14.2 \%$ (stone pine) and $21.2 \%$ (silver wattle).

Oxygen percent amounts averaged $27.9 \%$ for poplar clones, ranging between $30.85 \%$ (Wolterson) and $25.94 \%$ (Grimminge). The oxygen amount for torrefied biomass from common broom was $24.91 \%$. The correspondent oxygen amount values for roundwoods torrefied biomasses were higher, averaging $31.6 \%$ and ranging between $28.67 \%$ (poplar) and $37.34 \%$ (silver wattle). The oxygen percent loss averaged $34.2 \%$ for torrefied biomasses from poplar clones and $21.5 \%$ for torrefied roundwood biomasses. The correspondent value for common broom was $34 \%$. The oxygen percent amount loss for poplar clones ranged between 27\% (Wolterson) and 38\% (Grimminge and Ellert).

The average hydrogen percent amounts for torrefied biomasses from poplar clones and roundwood was of about $4.9 \%$ and $5.35 \%$, respectively. The hydrogen percent amount for common broom torrefied biomass was 5.52\%. The hydrogen amounts for torrefied biomasses from poplar clones ranged between $4.8 \%$ (Hees) and 5.12\% (AF2). The hydrogen amounts for roundwood torrefied biomasses ranged between $4.98 \%$ (silver wattle) and 5.53\% (stone pine). The percent hydrogen loss was of $6.7 \%$ for torrefied biomasses from roundwood and of $5.5 \%$ for torrefied biomasses from poplar clones. The correspondent value for common broom torrefied biomass was $4 \%$. The percent hydrogen loss for roundwood torrefied biomasses ranged between $4 \%$ (sally water) and 11\% (eucalyptus). The percent hydrogen loss for torrefied biomasses from poplar clones ranged 4\% (Brandaris, and $\mathrm{AF} 2$ ) and $8 \%$ for Hees and Bakan. The average ratios $\mathrm{O} / \mathrm{C}$ and $\mathrm{H} / \mathrm{C}$ of torrefied biomasses from poplar clones were 0.42 and 0.08 , respectively. For common broom torrefied biomass these ratios were 0.37 and 0.08 , respectively. The ratios $\mathrm{O} / \mathrm{C}$ and $\mathrm{H} / \mathrm{C}$ averaged 0.5 and 0.08 , respectively, for roundwood torrefied biomasses.
For the torrefied biomasses from poplar clones the ratio $\mathrm{O} / \mathrm{C}$ ranged between 0.38 (Grimminge) and 0.49 (Wolterson). The ratio $\mathrm{H} / \mathrm{C}$ values were similar for these biomasses. For the roundwood torrefied biomasses the ratios $\mathrm{O} / \mathrm{C}$ ranged between 0.44 (poplar) and 0.65 (silver wattle). As succeeded with poplar clones, ratio $\mathrm{H} / \mathrm{C}$ values were similar for these biomasses.

For biomasses from poplar clones from SRCs the losses of $\mathrm{H} / \mathrm{C}$ ratios with torrefaction ranged between $23.3 \%$ (AF2) and 29.2\% (Hees), averaging 26.4\%. For common broom biomass the $\mathrm{H} / \mathrm{C}$ loss was $21.7 \%$. For roundwood biomasses, the percent losses of $\mathrm{H} / \mathrm{C}$ ratios averaged $19.8 \%$, ranging between $17.4 \%$ for stone pine and $23.05 \%$ for silver wattle. The losses of ratios $\mathrm{O} / \mathrm{C}$ with torrefaction averaged $48.5 \%$ for biomasses for poplar clones, ranging between $40 \%$ (Wolterson) and $52.9 \%$ (Grimminge). For common broom biomass, the $\mathrm{O} / \mathrm{C}$ loss was $46.2 \%$. For roundwood biomasses, the percent losses of $\mathrm{O} / \mathrm{C}$ ratios averaged $32.6 \%$, ranging between $29.5 \%$ for eucalyptus and $37.5 \%$ for poplar.

\subsection{Correlation analysis}

\subsubsection{Proximate analysis}

Considering the proximate analysis and LHV for the whole set of biomasses, 25 significant correlations at $\mathrm{p}<$ 0.05 (in bold) with absolute values ranging between 0.58 and 0.98 were established between a group of 9 variables which were: $\%$ gain in fixed carbon, $\%$ LHV gain, $\%$ ash gain, $\%$ loss of volatiles, $\%$ fixed carbon, $\%$ LHV, $\%$ volatiles, $\%$ ash gain and $\%$ of mass loss. The $\%$ mass loss on torrefaction showed the higher number of significant correlations (7) with all the remaining variables, except ash amount.

The global correlation picture of proximate analysis for the sets of torrefied biomasses from poplar SRC and common broom was similar. The number of significant correlation was a bit smaller (15) among the same set of 9 variables. Six variables (\% gain in fixed carbon, LHV $\%$ gain, \% loss of volatiles, \% fixed carbon, LHV and \% volatiles) showed 5 significant correlations. Percent fixed carbon and LHV showed 5 significant correlations with all variables excepting $\%$ ashes and \% ash gain. Fixed carbon was highly correlated with \% loss of volatiles (0.95), volatiles (-0.98), LHV (0.88 each), LHV gain $(0.82)$ and $\%$ gain in fixed carbon (0.73). LHV showed high significant correlation with gain in LHV (0.97), with volatiles loss and fixed carbon $(0.88)$, gain in fixed carbon (0.77) and with volatiles (-0.83). Percent ashes and ash gain showed no significant correlations with any other variable. The variable \% LHV gain showed five significant correlations with variables: LHV (0.97), \% fixed carbon (0.82), \% volatiles $(-0.76), \%$ loss of volatiles $(0.78)$ and $\%$ gain in fixed carbon $(0.63)$. The LHV variable showed 5 significant correlations with other variables which were: \% gain in LHV (0.97), \% fixed carbon (0.88), \% loss of volatiles (0.88), \% volatiles $(-0.83)$ and $\%$ gain in fixed carbon $(0.77)$. The $\%$ mass loss on torrefaction, on the dataset of torrefied biomasses from poplar SRC and common broom, showed no significant correlation with other variables, indicating that the distinct characteristics of these biomasses, should be independent of the higher mass losses occurred in the lab scale experiments. 
The correlation matrix for torrefied biomass from roundwood species was totally different from the former two above, with only 4 significant correlations among the same set of 9 variables as before. Percent loss of volatiles showed the higher number of significant correlations (2) with gain in fixed carbon (0.86) and volatiles (-0.94). Other significant correlations were 0.91 between $\%$ ash and $\%$ ash gain and 0.89 between $\%$ fixed carbon and \% LHV gain. The variables LHV and \% mass loss showed no significant correlation with any other variable.

These correlations for LHV and proximate analysis showed thereby a much higher degree of interconnectedness between torrefied biomass variables from the set of poplar SRCs and common broom torrefied biomasses comparatively to correspondent variables from the set of roundwood species. The former set of torrefied biomasses showed the expectable correlations between LHV, \% gain in LHV, fixed carbon, volatiles and the respective gains and losses.

\subsubsection{Ultimate analysis}

A correlation analysis has also been made with 12 variables related to ultimate analysis and with changes of chemical elements, LHV and elementary ratios due to torrefaction ( $\%$ hydrogen, $\%$ carbon, $\%$ nitrogen, $\%$ oxygen, $\%$ elementary carbon gain, $\%$ oxygen loss, $\%$ hydrogen loss, $\%$ nitrogen gain, $\%$ torrefaction mass loss, $\%$ LHV gain, $\% / \mathrm{C}$ ratio loss and \% $\mathrm{O} / \mathrm{C}$ ratio loss).

The significant correlations among these variables within the dataset of whole woody biomasses totalized 35, with values ranging between -0.52 and 0.99 . The variable $\%$ $\mathrm{O} / \mathrm{C}$ loss was the one with the higher number of significant correlations (9).

The overall correlation picture for the same 12 variables with torrefied biomass properties from poplar clones and common broom was very different with 14 significant correlations in this dataset ranging between - 0.64, and 0.98 . The variable $\% \mathrm{O} / \mathrm{C}$ loss was the one with the higher number of significant correlations (5) with: \% oxygen loss (0.98), elementary carbon gain (0.93), \% carbon $(0.85), \%$ oxygen $(-0.73)$, and $\%(\mathrm{H} / \mathrm{C})$ ratio loss $(0.66)$.

The variable \% LHV gain showed only one significant correlation $(0.67)$ with the $\%$ loss of ratio $(\mathrm{H} / \mathrm{C})$. The oxygen \% loss showed significant correlations with \% elementary carbon $(0.92)$ and \% elementary carbon gain (0.86). The variables \% nitrogen gain and \% mass loss of torrefaction showed no significant correlation with any other variable.

The correlation matrix of torrefied biomasses from roundwood species showed 17 significant correlations and was not very distinct from these corresponding from poplar SRC and common broom dataset. In this dataset, the $\%(\mathrm{O} / \mathrm{C})$ loss showed three significant correlations with $\%$ LHV gain $(0.94), \%$ nitrogen gain $(0,84)$ and $\%$ oxygen loss (0.9).

These latter correlations showed that proximate analysis reflected on a much higher degree the overall behavior differences for torrefaction aptitude of the two sets biomasses comparatively to proximate analysis. The ratio $\mathrm{O} / \mathrm{C} \%$ loss was the variable with higher number of correlations in the matrices corresponding to the datasets for the whole and for the poplar and common broom torrefied biomasses.

\section{Discussion}

The torrefaction essays of the two sets of woody biomass occurred under a temperature of $265^{\circ} \mathrm{C}$, during a residence time of $15 \mathrm{~m}$ and a total heating cycle of $1 \mathrm{~h} 45 \mathrm{~m}$. These operative parameters were chosen from the expertise of the company YGE - Yser Green Energy SA on torrefaction and pelletizing. These physical conditions, can justify the mass loss profile observed, with average values of about $47 \%$ and $41 \%$, for the sets of torrefied biomasses from poplar SRC and common broom and roundwood, respectively. These values are higher than the $20 \%$ - $30 \%$ mass loss expectable under milder physical conditions (e.g., [9]; [10]; [11]; [12]).

This higher mass loss is reflected in a higher amount of flues gases and it is expected that a recirculation system operates, so that these hot gases can be conducted for use in the drying and reactor heating industrial steps. But, under constant physical conditions, the results of this experimental work, point to a clear aptitude of poplar clones from short rotation coppices cultivations and common broom for the torrefaction treatment. Poplars in general are increasingly used for biofuel production due to its high growth and biomass productivity, significant amount of hollocellulose (cellulose 42 to $49 \%$ and hemicelluloses from 16 to $23 \%$ ) and not too high lignin content (between 21 and 29\%) (e.g., [13]).

The higher aptitude for torrefaction observed in the set of biomasses including poplar SRC and common broom should be due to chemical structural characteristics pointed in the Introduction such as predominance of xylan type hemicelluloses or of $\beta-O-4$ bonds and syringyl content in lignin more susceptible to cleavage [14]. Thereby, the total degradation of hemicelluloses and partial degradation of lignin initiated by demethoxylation and $\beta-\mathrm{O}-4$ bond cleavage leads to a solid residual char enrichment in higher chemical rich and heating energy components of cellulose and lignin [15].

The correlation results, for proximate and ultimate analysis, can be indicative of pivot variables apt to parameterize the biomass torrefaction operation. These results showed that the structural changes in torrefied biomasses were mainly reflected on proximate analysis. Indeed, the correlation patterns for the set of poplar clones and common broom were dense, inasmuch that six variables exhibited 5 significant correlations each, showing the high level of interaction between LHV, LHV gain, fixed carbon amount, gain in fixed carbon, volatiles amount and loss of volatiles. The negative correlation between fixed carbon and volatiles was the highest on this dataset (-0.98), showing a clear opposite variation of these two variables. The LHV of torrefied biomasses of common broom and poplar clones was also highly correlated (0.97) with \% LHV gain, showing a selffulfilled potential for calorific power by these kinds of biomasses.

Regarding the roundwood biomasses, we regarded that the interaction of variables useful from a biofuels perspective, was much smaller. Indeed, the higher number of significant correlations was only two, concerning the correlation of $\%$ loss of volatiles with gain in fixed carbon $(0.86)$ and \% loss of volatiles ($0.94)$. 
The latter was the higher correlation in absolute value observed. The pattern of correlation for this dataset allow to detect additional interactions e.g., on LHV \% gain with $\%$ of fixed carbon (0.89) and \% ashes with \% ash gain (0.91).

The later was the only significant correlation involving ashes in the sets of torrefied biomasses from poplar clones and common broom and from roundwood species. Interesting was also the absence of any significant correlation involving the \% loss mass on torrefaction on both data sets, concerning proximate analysis.

This result is indicative of the fact that the highly relative mass loss, under the experimental conditions, didn't contribute to the differences on proximate analysis of the torrefied products. These should be due mainly to the structural differences of the two kinds of biomass: poplar clones and common broom on one hand and roundwood biomass on the other.

The correlation matrix structures of ultimate analysis results for the two kinds of biomasses are very similar, enhancing some relevance of $\mathrm{O} / \mathrm{C}$ ratio $\%$ loss on the torrefied biomass datasets, especially on the poplar clones and common broom dataset. Indeed, with the latter dataset, this ratio loss showed high significant correlations with \% elementary carbon gain $(0.93)$, elementary carbon $(0.85)$, hydrogen loss $(0.98)$, oxygen $\%$ amount $(-0.73)$ and $\mathrm{H} / \mathrm{C} \%$ loss $(0.66)$.

In the same way, high significant correlations were detected on the same dataset between elemental carbon with oxygen $\%$ amounts $(-0.98)$ and with \% oxygen loss (0.92).

With the roundwood torrefied biomass dataset, the variable $(\mathrm{O} / \mathrm{C}) \%$ loss showed significant correlations of 0.9 with $\%$ oxygen and 0.94 with LHV \% gain.

As mentioned above, \% mass loss on torrefaction was the variable with higher significant correlations (5) in this dataset, mainly -0.95 with $\%$ hydrogen, -0.91 with $\%$ elementary carbon and 0.91 with elementary oxygen. Mass loss \% showed no significant correlations in the dataset representative of poplar SRC clones and common broom. This evidence points to same causal relation between mass loss of torrefied biomasses from roundwood species and ultimate analysis variables.

The genetically improved biomasses from poplar clones used in this study, proved thereby to be also valuable for the aptitude of these feedstocks to torrefaction. Common broom, a widespread perennial shrub species occurring at forest areas has woody structural similarities with young juvenile plants of poplar clones justifying its similar aptitude to torrefaction.

\section{Conclusions}

This study evaluated the aptitude for torrefaction of the main Portuguese roundwood species and SRC poplar clones and common broom. Results of roundwood on torrefaction were comparable with results from other studies.

Absence of significant correlations between mass loss and proximate analysis variables for the set of torrefied biomasses common broom and poplar clones enhanced the role of biomass structure on the torrefaction behavior.
The joint analysis of correlation data and torrefied biomass proximate analysis variables allow to choose, within the torrefied biomasses from poplar clones and common broom, the clones Skado, Hees, Bakan and common broom as these with higher torrefaction aptitude. The criteria considered are the combination of high LHV (ranging from $23.81 \mathrm{MJkg}^{-1}$ and $25.05 \mathrm{MJkg}^{-1}$ ) high LHV \% gain (ranging between $25 \%$ and 36\%), lower \% volatiles (ranging between $54.66 \%$ and 61.28 $\%$ ), higher $\%$ loss of volatiles (ranging between $25 \%$ and $30 \%$ ), high \% fixed carbon (ranging between $35.89 \%$ and $41.8 \%$ ) and high \% fixed carbon gain (ranging between $51 \%$ and $53 \%$ ).

The same criteria, applied to the dataset of torrefied biomasses from roundwood species allow choosing eucalypt, silver wattle, maritime pine and mature poplar, for torrefaction purposes. In this case LHV ranges between $21.06 \mathrm{MJkg}^{-1}$ and $22.6 \mathrm{MJkg}^{-1}$, LHV \% gain ranges between $17 \%$ and $25 \%, \%$ of volatiles range between $65.53 \%$ and $68.47 \%, \%$ loss of volatiles ranges between $14 \%$ and $18 \%, \%$ of fixed carbon ranges between $29.33 \%$ and $33.35 \%$ and $\%$ of fixed carbon gain which ranges between $36 \%$ and $45 \%$. All these woody biomasses exist or can be cultivated in Portugal, turning thereby the torrefaction industry as feasible and determinant for woody biomass energetic conversion.

The variable $\mathrm{O} / \mathrm{C}$ ratio \% loss, which had some relevance and significant number correlations in torrefied biomasses datasets of poplar clones and common groom and roundwoods, showed a variation between $46 \%$ and $52 \%$ for the poplar clones Skado, Hees, Bakan and common broom. For eucalyptus, silver wattle, maritime pine and mature poplar the same variable ranges between $30 \%$ and $38 \%$.

It can be concluded, from the obtained results, that for a country like Portugal with large forest, shrubland and pasture areas, torrefaction can be promising for the optimizing of woody biomasses for bioenergy applications.

\section{Acknowledgments}

The authors would like to acknowledge the Portuguese company YGE - Yser Green Energy SA, Portugal, that allowed the execution of the laboratory tests. The current study was funded in part by Fundação para a Ciência e Tecnologia (FCT), under project UID/EMS/00151/2013 C-MAST, with reference POCI-01-0145-FEDER007718. J.P.S. Catalão acknowledges the support by FEDER funds through COMPETE 2020 and by Portuguese funds through FCT, under Projects SAICTPAC/0004/2015 - POCI-01-0145-FEDER-016434, POCI-01-0145-FEDER-006961, UID/EEA/50014/2013, $\mathrm{UID} / \mathrm{CEC} / 50021 / 2013$, and UID/EMS/00151/2013, and also funding from the EU 7th Framework Programme FP7/2007-2013 under GA no. 309048.

\section{References}

[1] A. C. Dias and L. Arroja, "Environmental impacts of eucalypt and maritime pine wood production in Portugal," J. Clean. Prod., vol. 37, pp. 368-376, 2012. 
[2] A. J. A. Santos, O. M. S. Anjos, and R. M. S. Simões, "Papermaking potential of Acacia dealbata and Acacia melanoxylon," Appita J., vol. 59, no. 1, 2006.

[3] J. S. Uva, "IFN6 - Áreas dos usos do solo e das espécies florestais de Portugal continental. Resultados preliminares.," 2013.

[4] T. Cerchiara et al., "Chemical composition, morphology and tensile properties of spanish broom (Spartium junceum L.) fibres in comparison with flax (Linum usitatissimum L.)," Fibres Text. East. Eur., vol. 104, no. 2, pp. 25-28, 2014.

[5] I. Dimitriou, H. Rosenqvist, and G. Berndes, "Slow expansion and low yields of willow short rotation coppice in Sweden; implications for future strategies," Biomass Bioenergy, vol. 35, no. 11, pp. 4613-4618, 2011.

[6] S. González-García, B. Mola-Yudego, I. Dimitriou, P. Aronsson, and R. Murphy, "Environmental assessment of energy production based on long term commercial willow plantations in Sweden," Sci. Total Environ., vol. 421-422, pp. 210-219, 2012

[7] B. Mola-Yudego, "Regional potential yields of short rotation willow plantations on agricultural land in northern Europe," Silva Fenn., vol. 44, no. 1, pp. 63-76, 2010.

[8] M. Brostr??m, A. Nordin, L. Pommer, C. Branca, and C. Di Blasi, "Influence of torrefaction on the devolatilization and oxidation kinetics of wood," J. Anal. Appl. Pyrolysis, vol. 96, pp. 100-109, 2012.

[9] J. Shankar Tumuluru, S. Sokhansanj, J. R. Hess, C. T. Wright, and R. D. Boardman, "REVIEW: A review on biomass torrefaction process and product properties for energy applications," Ind. Biotechnol., vol. 7, no. 5, pp. 384-401, 2011.
[10] B. Acharya, I. Sule, and A. Dutta, "A review on advances of torrefaction technologies for biomass processing," Biomass Convers. Biorefinery, vol. 2, no. 4, pp. 349-369, 2012.

[11] M. Walkowiak and M. Bartkowiak, "The kinetics of the thermal decomposition of the willow wood (Salix viminalis L.) exposed to the torrefaction process," Drewno, vol. 187, no. 187, pp. 37-49, 2012.

[12] Q. V. Bach, R. a. Khalil, K. Q. Tran, and O. Skreiberg, "Torrefaction kinetics of norwegian biomass fuels," Chem. Eng. Trans., vol. 37, pp. 49-54, 2014.

[13] P. Sannigrahi, A. J. Ragauskas, and G. A. Tuskan, "Poplar as a feedstock for biofuels: A review of compositional characteristics," Biofuels, Bioproducts and Biorefining, vol. 4, no. 2. pp. 209-226, 2010.

[14] P. Nanou, W. J. J. Huijgen, M. C. Carbo, and J. H. A. Kiel, "The role of lignin in the densification of torrefied wood in relation to the final product properties," Biomass and Bioenergy, 2016.

[15] B. Xiao, X. F. Sun, and R. Sun, "Chemical, structural, and thermal characterizations of alkali-soluble lignins and hemicelluloses, and cellulose from maize stems, rye straw, and rice straw," Polym. Degrad. Stab., vol. 74, no. 2, pp. 307-319, 2001. 